\title{
Neurobiology of Escalated Aggression and Violence
}

\author{
Klaus A. Miczek, ${ }^{1,2}$ Rosa M. M. de Almeida, ${ }^{3}$ Edward A. Kravitz, ${ }^{4}$ Emilie F. Rissman, ${ }^{5}$ Sietse F. de Boer, ${ }^{6}$ and \\ Adrian Raine ${ }^{7}$ \\ ${ }^{1}$ Department of Psychology, Tufts University, Medford, Massachusetts 02155, 2Departments of Psychiatry, Pharmacology and Experimental Therapeutics, \\ and Neuroscience, Tufts University School of Medicine, Boston, Massachusetts 02110, ${ }^{3}$ Laboratory of Neuroscience, Universidade do Vale do Rio dos Sinos, \\ São Leopoldo, Rio Grande do Sul, Brazil, ${ }^{4}$ Department of Neurobiology, Harvard University Medical School, Boston, Massachusetts 02115, ${ }^{5}$ Department of \\ Biochemistry and Molecular Genetics, University of Virginia School of Medicine, Charlottesville, Virginia 22908, ${ }^{6}$ Department of Behavioral Physiology, \\ University of Groningen, 9700 AB Groningen, The Netherlands, and 7Department of Criminology, Psychiatry, and Psychology, University of Pennsylvania, \\ Philadelphia, Pennsylvania 19104
}

Psychopathological violence in criminals and intense aggression in fruit flies and rodents are studied with novel behavioral, neurobiological, and genetic approaches that characterize the escalation from adaptive aggression to violence. One goal is to delineate the type of aggressive behavior and its escalation with greater precision; second, the prefrontal cortex (PFC) and brainstem structures emerge as pivotal nodes in the limbic circuitry mediating escalated aggressive behavior. The neurochemical and molecular work focuses on the genes that enable invertebrate aggression in males and females and genes that are expressed or suppressed as a result of aggressive experiences in mammals. The fruitless gene, immediate early genes in discrete serotonin neurons, or sex chromosome genes identify sexually differentiated mechanisms for escalated aggression. Male, but not female, fruit flies establish hierarchical relationships in fights and learn from previous fighting experiences. By manipulating either the fruitless or transformer genes in the brains of male or female flies, patterns of aggression can be switched with males using female patterns and vice versa. Work with Sts or Sry genes suggests so far that other genes on the $\mathrm{X}$ chromosomes may have a more critical role in female mouse aggression. New data from feral rats point to the regulatory influences on mesocortical serotonin circuits in highly aggressive animals via feedback to autoreceptors and via GABAergic and glutamatergic inputs. Imaging data lead to the hypothesis that antisocial, violent, and psychopathic behavior may in part be attributable to impairments in some of the brain structures (dorsal and ventral PFC, amygdala, and angular gyrus) subserving moral cognition and emotion.

Key words: aggression; alcohol; genetics; learning; prefrontal cortex; serotonergic 1A receptor; serotonin; sex difference

Research on aggression and violence is pursued by social and biological scientists with profoundly divergent approaches. At present, the schism between these approaches promises to be overcome by advancing our knowledge of the molecular events through which social experiences sculpt future aggressive acts. Insights into the gene-environment interactions are critical for the way in which the criminal justice and the public health systems deal with aggression and violence. Neurobiological research of aggressive behavior is emerging from several shameful episodes during the past century ranging from the eugenics movement to lobotomies to stigmatizing individuals with phrenologically defined biomarkers (Valenstein, 1987). As a matter of fact, the World Report on Violence and Health (2002) by the World Health Organization ignores the neuroscience approach to these

\footnotetext{
Received Aug. 1, 2007; revised Aug. 24, 2007; accepted Sept. 3, 2007.

This work was supported by National Institutes of Health Grants AA013983 and DA02632 (K.A.M.), NS055218 (E.F.R.), and HD42259 (A.R.), National Institute of General Medical Sciences Grants 067645 and 072411 (E.A.K.), National Science Foundation Grant IBN 0090730 (E.A.K.), Universidade do Vale do Rio dos Sinos, and Conselho Nacional de Desenvolvimento Cientifico e Tecnológico and Coordenação de Aperfeiçoamento de Pessoal de Nível Superior (R.M.M.A.)

Correspondence should be addressed to Klaus A. Miczek, Tufts University, 530 Boston Avenue (Bacon Hall), Medford, MA 02155. E-mail: klaus.miczek@tufts.edu.

D01:10.1523/JNEUROSCI.3500-07.2007

Copyright $\odot 2007$ Society for Neuroscience $\quad 0270-6474 / 07 / 2711803-04 \$ 15.00 / 0$
}

behaviors altogether (Krug et al., 2002). Here we point to several emerging successes in behavioral and molecular biology of aggression research that may have important implications not only for diagnosis, prevention, and treatment but also for guidance of public and judicial policies.

Aggression as an adaptive behavior in males and females: quantitative ethological analysis

Classic ethological studies have focused on aggression because this behavior is typical for both invertebrate and vertebrate species during particular situations of conflict. The study of the phylogeny, ontogeny, and functional significance of these complex behavioral adaptations in different kinds of aggressive confrontations provides the foundation for neurobiological analyses. The salient acts, postures, and communicative signals of aggressive behavior follow an intricate temporal and sequential organization, some are common to males and females, and others are sexually dimorphic (Nilsen et al., 2004; Miczek et al., 2007). In a newly studied invertebrate model, male fruit flies (Drosophila melanogaster) establish hierarchical relationships in fights, whereas female flies do not. Like mammals, flies learn from previous fighting experiences and use this information for establishing and maintaining hierarchical relationships (Yurkovic et al., 
2006). In adult male and female mice, exposure to androgenic steroids during critical prenatal and postnatal periods are among the distal determinants of subsequent aggressive behavior, and these influences during early development are readily seen in adult male and female aggression in mice (Vom Saal and Bronson, 1978; Mann and Svare, 1983). An important task is to extend the insights from species-normative aggression to clinical concerns with pathological aggression.

\section{The need for valid experimental models of escalated aggression}

Examples from clinical research on aggressive behavior illustrate the focus on behavioral phenotypes that exceed the speciesnormative patterns and represent behavioral pathologies (Raine and Yang, 2006). New experimental models of escalated aggressive behavior in mice, hamsters, and rats attempt to translate more adequately to clinically problematic violent outbursts (Miczek et al., 2004, 2007; Haller and Kruk, 2006; Nelson and Trainor, 2007). Many experimental models rely on noxious environmental stimuli, neural lesions, or pharmacological or genetic manipulations to engender aggressive behavior in otherwise placid laboratory animals (de Boer and Koolhaas, 2005). For example, the preferential use of mice of the 129 Sv strain for targeted gene manipulations triggers aggressive behavior in a strain that, uncharacteristic for this pugnacious species, usually does not fight (Miczek et al., 2001). In extension of the original account in mice (Ginsburg and Allee, 1942), a new model uses feral-derived resident rats that escalate their aggressive behavior as a result of repeated victories in aggressive confrontations with intruders (i.e., short latency, high frequency and intensity, persistent attacks that are indiscriminate of opponent, impervious to signals of submission, and potentially injurious) (de Boer and Koolhaas, 2005). This methodological approach highlights the rewarding nature of aggressive behavior that has begun to be characterized in terms of its neurobiology in mice (Fish et al., 2002, 2005, 2007).

\section{Ethical dilemma of aggression research}

To be clinically relevant, experimental model systems for aggressive behavior need to be valid, and this development crystallizes a central ethical dilemma of aggression research, namely harm and injury. Two countervailing principles govern this research: face validity is achieved when the behavior is potentially harmful and injurious, yet, at the same time, every ethical research guideline emphasizes the reduction and avoidance of the risk to be harmed or injured. Each research question and protocol needs to probe how much harm and injury is necessary or acceptable to generate scientifically valid information that can be translated into concerns of the public health system. Although this discussion focuses primarily on mammals, it is pertinent to all species.

\section{The genetics of learning to be aggressive}

New studies show how the fruitless gene in D. melanogaster, which has been shown previously to be necessary and sufficient in determining whether a fly courts males or females, is also a critical determinant for how flies fight. By manipulating either the fruitless or transformer genes in the brains of male or female flies, patterns of aggression can be switched with males using female patterns of aggression or females using male patterns (Vrontou et al., 2006). Male protein products of fruitless $\left(\mathrm{Fru}^{\mathrm{M}}\right)$ normally are found in 20 clusters of neurons in male CNS. Mechanistically, the expression of $\mathrm{Fru}^{\mathrm{M}}$ must occur in a particular one of these 20 clusters of neurons in female flies to make the females fight like males (Y. B. Chan and E. A. Kravitz, unpublished observations) (Kimura et al., 2005). Furthermore, Certel, Kravitz, and coworkers have demonstrated that the amine octopamine, the invertebrate homolog to norepinephrine, is involved in the behavioral choice between courtship and aggression in male flies (Certel et al., 2007) (S. J. Certel, unpublished observations). Of the $\sim 80$ octopamine neurons normally found in the fly CNS, three within the subesophageal ganglion show colocalization of the amine with $\mathrm{Fru}^{\mathrm{M}}$. Eliminating $\mathrm{Fru}^{\mathrm{M}}$ expression in these three neurons by either feminizing the neurons in otherwise male brains or eliminating $\mathrm{Fru}^{\mathrm{M}}$ by RNA interference yields the same behavioral phenotype as eliminating octopamine; male flies have difficulty determining whether to court or fight other males.

\section{Sex chromosome genes and female aggression}

In complement to the early hypothesis that the Sry (sex determining region $\mathrm{Y}$ ) gene, located on the $\mathrm{Y}$ chromosome, acted as a candidate gene for differentiating aggression between sexes and among strains of mice (Maxson, 1996), Rissman and colleagues investigate Sry and another sex chromosome candidate gene, Sts (steroid sulfatase) (E. F. Rissman, unpublished data). This latter gene encodes the steroid sulfatase enzyme; it is located on the pseudoautosomal region of the $\mathrm{Y}$ chromosome and is expressed in both sexes. It is pivotal in the regulation of neurosteroid biosynthesis and altered brain activity of Sts, attributable to either genetic (Le Roy et al., 1999) or pharmacological (Nicolas et al., 2001) manipulations, and is correlated with levels of aggression among male mice.

Although resting brain levels of Sts are similar in both sexes, it increases dramatically in females after parturition and during lactation, corresponding to the onset of maternal aggression in many species. Rissman and coworkers hypothesized that Sts may exert a critical role in aggression expressed by females, but data from females with sex chromosome aneuploidy appear negative so far. Ongoing work using females that have a Y chromosome with spontaneous deletion of the Sry testes determining gene (referred to as $\mathrm{Y}^{-}$) shows that the Sry gene is not needed for enhanced aggression when a resident female confronts an intruder female. Moreover, females with $\mathrm{XY}^{-}$chromosome complements initiate offensive attacks on intruders faster than XX females (Gatewood et al., 2006). So far, this work shows that, although sex chromosome complement is involved in aggression, an X or Y gene other than Sts or Sry may have more critical roles in female aggression.

\section{Serotonin-revisited}

Brain serotonin (5-HT) has been implicated in the neurobiological mechanisms of aggression and violence more than any other molecule in the brain (Miczek et al., 2002, 2007; Kravitz and Huber, 2003). The early proposal of a tropotrophic action of this evolutionary ancient indolamine was extended to a calming effect on impulsively aggressive behavior, and this characterization was supported by correlational data from low CSF metabolite levels and blunted responses to serotonergic drug challenges in violent individuals (Linnoila et al., 1983; Coccaro, 1989). Recent data confirm lower levels of release of 5-HT in the nucleus accumbens and in prefrontal cortex (PFC) in rats with extensive experiences of aggressive behavior (Van Erp and Miczek, 2000; de Boer et al., 2003; Ferrari et al., 2003). Tonic brain levels of 5-HT decrease as a consequence of acquiring repeated victorious experiences. In contrast, the level of adaptive aggressive behavior is positively related to basal CSF concentrations of 5-HT in wild-type rats (Van der Vegt et al., 2003a,b). These data point to opposite roles 
of mesocortical serotonin activity in adaptive and escalated forms of aggressive behavior.

The regulation of 5-HT release from serotonergic neurons via $5-\mathrm{HT}_{1 \mathrm{~A}}$ and $5-\mathrm{HT}_{1 \mathrm{~B}}$ autoreceptors and via GABAergic and glutamatergic input to these neurons have emerged as candidate mechanisms for the transition between adaptive and escalated types of aggressive behavior. Evidence points to potent and selective anti-aggressive effects of $5-\mathrm{HT}_{1 \mathrm{~A}}$ and $5-\mathrm{HT}_{1 \mathrm{~B}}$ receptor agonists on both somatodendritic autoreceptors and on postsynaptic receptors in male and female rodents (de Almeida and Lucion, 1997; de Boer and Koolhaas, 2005; Olivier and Van Oorschot, 2005; Bannai et al., 2007). Highly aggressive rats are characterized by upregulated somatodendritic $5-\mathrm{HT}_{1 \mathrm{~A}}$ and terminal $5-\mathrm{HT}_{1 \mathrm{~B}}$ autoreceptor (Caramaschi et al., 2007), and this activity can be further enhanced by victorious aggressive experiences. Based on their recent findings, de Boer and colleagues hypothesize that the enhanced inhibitory autoreceptor function is a normal compensatory adaptation to the more reactive state of the brain 5-HT system in highly aggressive animals. They further speculate that an excessive activation (i.e., overshoot) of an autoreceptor brake may be a causative link in the cascade of events leading to the hypofunction of 5-HT neurons that characterizes violent and pathological forms of aggressive behavior.

\section{5-HT receptor gene expression in PFC}

In rodents, $5-\mathrm{HT}_{1}$ and $5-\mathrm{HT}_{2}$ receptor genes are expressed at lower levels in the PFC of individuals who engage in escalated aggression after consumption of alcohol relative to those who fight at a species-typical level (Chiavegatto et al., 2007). Intact alcohol-heightened and other escalated forms of aggression are potently inhibited by activation of $5-\mathrm{HT}_{1 \mathrm{~B}}$ receptors in subregions of the prefrontal cortex, possibly involving terminal autoreceptors or postsynaptic heteroreceptors (Faccidomo et al., 2005; de Almeida et al., 2006). If this is attributable to actions on postsynaptic receptors, compromised glutamatergic feedback from the prefrontal cortex to the raphe nuclei may serve as a necessary link for the expression of escalated aggression to be expressed. A focus on receptor pools in the prefrontal cortex is consistent with imaging data obtained from violent psychopaths, although in the latter case the anatomical resolution is more limited.

\section{Brain systems common to violence and moral decision making}

An increasing body of brain imaging research is documenting functional and structural brain impairments in antisocial and violent populations (Raine and Yang, 2006). Recent imaging research also is beginning to elucidate the neural correlates of moral decision making in normal individuals (Greene et al., 2001; Moll et al., 2005). Key areas found to be functionally or structurally impaired in antisocial populations include dorsal and ventral regions of the PFC, amygdala, hippocampus, angular gyrus, anterior cingulate, and temporal cortex (Raine and Yang, 2006). Regions most commonly activated in moral judgment tasks consist of the polar/medial and ventral PFC, amygdala, angular gyrus, and posterior cingulate (Raine and Yang, 2006). Although the overlap is by no means complete, some common ground exists between the neural circuitry underlying antisocial, violent behavior and moral decision making. Raine hypothesizes that the rulebreaking behavior common to antisocial, violent, and psychopathic individuals may in part be attributable to impairments in some of the structures (dorsal and ventral PFC, amygdala, and angular gyrus) subserving moral cognition and emotion. If of- fenders are not fully responsible for the source of the brain dysfunction that impairs their moral decision making, this raises significant neuroethical issues regarding the appropriate level of punishment for those who show morally inappropriate acts.

\section{Discussion}

A research agenda should consider the following points emanating from the recent findings in various model systems.

(1) Advances in understanding of experience-dependent and sexually dimorphic gene expression need to be translated into the clinical practice of diagnosing and treating pathologically violent individuals. The more accessible invertebrate and rodent model systems demonstrating gene-environment interactions should enlighten the search for the primate counterparts of these mechanisms.

(2) Interdisciplinary rivalries are rendered irrelevant as the molecular mechanisms of salient social experiences and learning during aggressive confrontations are deciphered. The next step for the study of aggressive behavior should be to elucidate how the molecular mechanisms underlying these salient experiences interact with genetic and environmental factors that predispose some individuals to engage in escalated aggressive behavior.

(3) Mesocortical serotonin circuits are intricately regulated via feedback from autoreceptors and via GABAergic and glutamatergic inputs. Future work must take into account the regional and temporal specificity of the molecular changes taking place during the transition from adaptive to escalated aggressive behavior.

(4) Neuroethical concerns require discussion in open discourse among representatives of the criminal justice system, psychiatry, neuroscience, and the social sciences.

\section{References}

Bannai M., Fish EW, Faccidomo S, Miczek KA (2007) Anti-aggressive effects of agonists at $5-\mathrm{HT}_{1 \mathrm{~B}}$ receptors in the dorsal raphe nucleus of mice. Psychopharmacology 193:295-304.

Caramaschi D, de Boer SF, Koolhaas JM (2007) Differential role of the $5-\mathrm{HT}_{1 \mathrm{~A}}$ receptor in aggressive and non-aggressive mice: an across-strain comparison. Physiol Behav 90:590-601.

Certel SJ, Savella MG, Schlegel DCF, Kravitz EA (2007) Modulation of Drosophila male behavioral choice. Proc Natl Acad Sci USA 104:4706-4711.

Chiavegatto S, Quadros IMH, Trindade A, Ambar G, Miczek KA (2007) Selective reduction of prefrontal cortex serotonin receptors gene expression in alcohol-heightened aggressive mice. Soc Neurosci Abstr 33:531.24.

Coccaro EF (1989) Central serotonin and impulsive aggression. Br J Psychiatry 155:52-62.

de Almeida RM, Rosa MM, Santos DM, Saft DM, Benini Q, Miczek KA (2006) $5-\mathrm{HT}_{1 \mathrm{~B}}$ receptors, ventral orbitofrontal cortex, and aggressive behavior in mice. Psychopharmacology 185:441-450.

de Almeida RMM, Lucion AB (1997) 8-OH-DPAT in the median raphe, dorsal periaqueductal gray and corticomedial amygdala nucleus decreases, but the medial septal area it can increase maternal aggressive behavior in rats. Psychopharmacology 134:392-400.

de Boer SF, Koolhaas JM (2005) 5- $\mathrm{HT}_{1 \mathrm{~A}}$ and $5-\mathrm{HT}_{1 \mathrm{~B}}$ receptor agonists and aggression: a pharmacological challenge of the serotonin deficiency hypothesis. Eur J Pharmacol 526:125-139.

de Boer SF, Van Der Vegt BJ, Koolhaas JM (2003) Individual variation in aggression of feral rodent strains: a standard for the genetics of aggression and violence? Behav Genet 33:485-501.

Faccidomo S, Bannai M, van Trigt RL, DeBold JF, Miczek KA (2005) Alcohol-heightened aggression and corticolimbic 5-HT: reverse microdialysis and microinjection of $5-\mathrm{HT}_{1 \mathrm{~B}}$ agonists in male mice. Soc Neurosci Abstr 31:76.18.

Ferrari PF, Van Erp AMM, Tornatzky W, Miczek KA (2003) Accumbal dopamine and serotonin in anticipation of the next aggressive episode in rats. Eur J Neurosci 17:371-378.

Fish EW, DeBold JF, Miczek KA (2002) Aggressive behavior as a reinforcer 
in mice: activation by allopregnanolone. Psychopharmacology 163:459-466.

Fish EW, De Bold JF, Miczek KA (2005) Escalated aggression as a reward: corticosterone and $\mathrm{GABA}_{\mathrm{A}}$ receptor positive modulators in mice. Psychopharmacology 182:116-127.

Fish EW, McKenzie-Quirk SD, Bannai M, Miczek KA (2007) 5- HT $_{1 \mathrm{~B}}$ receptor inhibition of alcohol-heightened aggression in mice: comparison to drinking and running. Psychopharmacology, in press.

Gatewood JD, Wills A, Shetty S, Xu J, Arnold AP, Burgoyne PS, Rissman EF (2006) Sex chromosome complement and gonadal sex influence aggressive and parental behaviors in mice. J Neurosci 26:2335-2342.

Ginsburg B, Allee WC (1942) Some effects of conditioning on social dominance and subordination in inbred strains of mice. Physiol Zool 15:485-506.

Greene JD, Sommerville RB, Nystrom LE, Darley JM, Cohen JD (2001) An fMRI investigation of emotional engagement in moral judgment. Science 293:2105-2108

Haller J, Kruk MR (2006) Normal and abnormal aggression: human disorders and novel laboratory models. Neurosci Biobehav Rev 30:292-303.

Kimura K, Ote M, Tazawa T, Yamamoto D (2005) Fruitless specifies sexually dimorphic neural circuitry in the Drosophila brain. Nature 438:229-233.

Kravitz EA, Huber R (2003) Aggression in invertebrates. Curr Opin Neurobiol 13:736-743.

Krug EG, Dahlberg LL, Mercy JA, Zwi AB, Lozito R (eds.) (2002) World report on violence and health. Geneva: World Health Organization.

Le Roy I, Mortaud S, Tordjman S, Donsez-Darcel E, Carlier M, Degrelle H, Roubertoux PL (1999) Genetic correlation between steroid sulfatase concentration and initiation of attack behavior in mice. Behav Genet 29:131-136

Linnoila M, Virkkunen M, Scheinin M, Nuutila A, Rimon R, Goodwin FK (1983) Low cerebrospinal fluid 5-hydroxyindoleacetic acid concentration differentiates impulsive from nonimpulsive violent behavior. Life Sci 33:2609-2614.

Mann MA, Svare B (1983) Prenatal testosterone exposure elevates maternal aggression in mice. Physiol Behav 30:503-507.

Maxson SC (1996) Searching for candidate genes with effects on an agonistic behavior, offense, in mice. Behav Genet 26:471-475.

Miczek KA, Maxson SC, Fish EW, Faccidomo S (2001) Aggressive behavioral phenotypes in mice. Behav Brain Res 125:167-181.

Miczek KA, Fish EW, DeBold JF, de Almeida RMM (2002) Social and neural determinants of aggressive behavior: pharmacotherapeutic targets at serotonin, dopamine and $\gamma$-aminobutyric acid systems. Psychopharmacology 163:434-458

Miczek KA, Faccidomo S, de Almeida RMM, Bannai M, Fish EW, DeBold JF
(2004) Escalated aggressive behavior: new pharmacotherapeutic approaches and opportunities. Ann NY Acad Sci 1036:336-355.

Miczek KA, Faccidomo SP, Fish EW, DeBold JF (2007) Neurochemistry and molecular neurobiology of aggressive behavior. In: Behavioral neurochemistry, neuroendocrinology and molecular neurobiology (Blaustein J, ed), pp 285-336. New York: Springer.

Moll J, Oliveira-Souza R, Moll FT, Ignacio FA, Bramati IE, Caparelli-Daquer EM, Eslinger PJ (2005) The moral affiliations of disgust-a functional MRI study. Cogn Behav Neurol 18:68-78.

Nelson RJ, Trainor BC (2007) Neural mechanisms of aggression. Nat Neurosci Rev 8:536-546.

Nicolas LB, Pinoteau W, Papot S, Routier S, Guillaumet G, Mortaud S (2001) Aggressive behavior induced by the steroid sulfatase inhibitor COUMATE and by DHEAS in CBA/H mice. Brain Res 922:216-222.

Nilsen SP, Chan YB, Huber R, Kravitz EA (2004) Gender-selective patterns of aggressive behavior in Drosophila melanogaster. Proc Natl Acad Sci USA 101:12342-12347.

Olivier B, Van Oorschot R (2005) $5-\mathrm{HT}_{1 \mathrm{~B}}$ receptors and aggression: a review. Eur J Pharmacol 526:207-217.

Raine A, Yang Y (2006) The anatomical bases of psychopathy: a review of brain imaging findings. In: Handbook of psychopathy (Patrick CJ, ed), pp 278-295. New York: Guilford.

Valenstein ES (1987) Great and desperate cures: the rise and decline of psychosurgery and other radical treatments for mental illness. New York: Harper Collins.

Van der Vegt BJ, Lieuwes N, van de Wall EH, Kato K, Moya-Albiol L, Martinez-Sanchis S, de Boer SF, Koolhaas JM (2003a) Activation of serotonergic neurotransmission during the performance of aggressive behavior in rats. Behav Neurosci 117:667-674.

Van der Vegt BJ, Lieuwes N, Cremers TIFH, de Boer SF, Koolhaas JM (2003b) Cerebrospinal fluid monoamine and metabolite concentrations and aggression in rats. Horm Behav 44:199-208.

Van Erp AMM, Miczek KA (2000) Aggressive behavior, increased accumbal dopamine, and decreased cortical serotonin in rats. J Neurosci 20:9320-9325.

Vom Saal FS, Bronson FH (1978) Inutero proximity of female mouse fetuses to males: effect on reproductive-performance during later life. Biol Reprod 19:842-853.

Vrontou E, Nilsen SP, Demir E, Kravitz EA, Dickson BJ (2006) fruitless regulates aggression and dominance in Drosophila. Nat Neurosci 9:1469-1471

Yurkovic A, Wang O, Basu AC, Kravitz EA (2006) Learning and memory associated with aggression in Drosophila melanogaster. Proc Natl Acad Sci USA 103:17519-17524. 